\title{
Synthesis, structure, thermal and NLO characterization of 4-hydroxy tetramethylpiperazinium picrate crystals
}

\author{
T DHANABAL $^{\mathrm{a}}$, G AMIRTHAGANESAN $^{\mathrm{a}, *}$, M DHANDAPANI $^{\mathrm{a}}$ and SAMAR K DAS ${ }^{\mathrm{b}}$ \\ ${ }^{a}$ Department of Chemistry, Sri Ramakrishna Mission Vidyalaya College of Arts and Science, \\ Coimbatore 641 020, India \\ ${ }^{\mathrm{b}}$ School of Chemistry, University of Hyderabad, Hyderabad 500 046, India \\ e-mail: profga@yahoo.co.in
}

MS received 18 October 2011; revised 5 March 2012; accepted 4 April 2012

\begin{abstract}
Good quality single crystals of 4-hydroxy tetramethylpiperazinium picrate (TMPP) were grown by slow evaporation solution growth method at room temperature. The average dimensions of the grown crystals were $0.6 \times 0.2 \times 0.2 \mathrm{~cm}^{3}$. The solubility of the compound was estimated using methanol and acetone. The elemental analysis confirms the formation of the compound in the stoichiometric proportion. The UV-visible transmittance study indicates that the crystal possesses minimum transmittance at $370 \mathrm{~nm}$ and no absorption at 470-900 nm. The Bragg peaks obtained in the powder X-ray diffraction pattern confirm its crystallinity. The thermal behaviour of the crystal was investigated using thermogravimetric (TG) and differential thermal analysis (DTA) techniques. The structure of the compound was determined by using single crystal X-ray diffraction method. The compound was found to be crystallize in the monoclinic space group P2 $2_{(1)} / \mathrm{c}(\mathrm{a}=6.9513(8) \AA$, $\left.\mathrm{b}=11.8016(14) \AA, \mathrm{c}=22.018(2) \AA, \alpha=90.00^{\circ}, \beta=92.575(2)^{\circ}, \gamma=90.00^{\circ}\right)$. The thermal anomalies observed in the differential scanning calorimetry (DSC) heating and cooling cycles indicate the occurrence of first order phase transition. Fourier transform infrared (FTIR) and polarized Raman spectral analyses were used to confirm the presence of various functional groups in the compound. The nonlinear optical property (NLO) of the crystal was analysed by Kurtz-Perry powder technique and found that the compound has SHG efficiency 1.5 times greater that of potassium dihydrogen phosphate (KDP).
\end{abstract}

Keywords. Crystal growth; thermal analysis; differential scanning calorimetry; nonlinear optical materials; single crystal X-ray diffraction; FTIR spectrum.

\section{Introduction}

Picric acid forms crystalline picrates of various organic molecules through ionic, hydrogen bonding and $\pi$ $\pi$ interactions. ${ }^{1}$ It is known that picric acid acts not only as an acceptor to form various $\pi$ stacking complexes with other aromatic molecules but also as an acidic ligand to form salts through specific electrostatic or hydrogen bond interactions. ${ }^{2}$ Bonding of electron donor/acceptor picric acid molecules strongly depends on the nature of the partners. The linkage could involve not only electrostatic interactions but also the formation of molecular complexes. ${ }^{3}$

Many new organic crystals have been examined based on the predictive molecular engineering approach and have been shown to have potential applications. ${ }^{4}$ Other advantages of organic compounds involve amenability for synthesis, multifunctional substitution, higher resistance to optical damage and maneuverability for device application etc. ${ }^{5}$ Molecular flexibility of

*For correspondence organic materials is an added advantage to enhance the nonlinear optical properties in a desired manner. ${ }^{6}$ In addition, they have large structural diversity. By adopting molecular engineering methods in chemical synthesis one can easily refine the optical properties of organic molecules. ${ }^{7}$ Picric acid forms crystalline picrate salts with various organic molecules by virtue of its acidic nature and forms salts through specific electrostatic or hydrogen bonding interactions. ${ }^{8}$ The various organic sub-networks induce noncentrosymmetry in the bulk and enhance the thermal and mechanical stabilities through hydrogen bonding interactions. ${ }^{9,10}$

In the present investigation, the growth and structural aspects of 4-hydroxy tetramethylpiperazinium picrate have been studied (hereafter abbreviated as TMPP). The crystals were characterized by solubility study, elemental analysis, powder X-ray diffraction method, UV-visible, thermal analyses (TG-DTA and DSC), single crystal XRD, fourier transform infrared (FTIR), polarized Raman spectroscopic techniques. The NLO property of the crystal has also been studied. 


\section{Experimental}

\subsection{Materials}

Analytical grades of 4-hydroxy tetramethylpiperazine and picric acid were purchased from Sigma Aldrich and used without further purification. The solvent methanol used is HPLC grade.

\subsection{Synthesis of TMPP crystals}

Single crystals of TMPP were grown by slow evaporation solution growth method at room temperature. Methanolic solutions containing analytical grades of one mole of 4-hydroxy tetramethylpiperazine and one mole of picric acid were prepared separately. The two solutions were mixed together and stirred well using mechanical stirrer for about $6 \mathrm{~h}$ to get a homogeneous solution and the resulting solution was filtered into a clean dry beaker using a Whatman 40 filter paper. After filtration, the filtrate was kept in dust-free environment for crystallization. The beaker was covered by an ordinary filter paper. Care was taken to minimize the temperature gradient and mechanical shock.

Under the experimental conditions, bright, transparent and yellow coloured TMPP crystals (scheme 1) were obtained. Crystallization took place within 15 to 20 days with dimensions of $0.6 \times 0.2 \times 0.2 \mathrm{~cm}^{3}$. The crystals were collected from the mother liquid using a clean forcep.

\subsection{Physical measurements}

The elemental analysis of the compound was carried out using a Flash 1112 SERIES EA analyzer. The optical transmittance spectrum of the complex was recorded using Lambda $35 \mathrm{UV}$-visible spectrophotometer in the wavelength range from 250 to $900 \mathrm{~nm}$. The powder XRD pattern of compound was obtained using Phillips PW3710 diffractometer with $\mathrm{Cu} \mathrm{K} \alpha$ radiation $(\lambda=1.54060 \AA)$ at room temperature and the sample was scanned over the range of $0-75^{\circ}$ at a scan rate of $10 \% \mathrm{~min}$. Thermal analyses were carried out using a STA 409 PC thermal analyzer under nitrogen atmosphere at a heating rate of $10 \mathrm{~K} / \mathrm{min}$. The low temperature DSC of the compound was obtained using a METTLER TOLEDO instrument under nitrogen atmosphere. The sample was cooled from $10^{\circ} \mathrm{C}$ to $-150^{\circ} \mathrm{C}$ and heated back from $-150^{\circ} \mathrm{C}$ to $10^{\circ} \mathrm{C}$ in the heating run. The FTIR spectrum of the compound was recorded on a JASCO-5300 FTIR spectrophotometer model instrument using $\mathrm{KBr}$ pellet technique at room temperature. The polarized Raman spectrum of the compound was analysed by using a Confocal Raman Microscope (CRM - Alpha 300S). The second harmonic generation (SHG) efficiency of the grown crystal was analysed using Kurtz-Perry powder technique.

\section{$2.4 X$-ray crystal structure determination}

The crystallographic data for the compound has been collected at $298 \mathrm{~K}$ on a Bruker SMART APEX CCD, area detector system $[\lambda(\mathrm{Mo} K \alpha)=0.7103 \AA]$, graphite monochromator, 2400 frames were recorded with an $\omega$ scan width of $0.3^{\circ}$, each for $10 \mathrm{~s}$, crystal-detector distance $60 \mathrm{~mm}$, collimator $0.5 \mathrm{~mm}$. Data reduction by SAINTPLUS, ${ }^{11}$ absorption correction using an empirical method SADABS, ${ }^{12}$ structure solution using SHELXS-97 ${ }^{13}$ and refined using SHELXL-97. ${ }^{14}$ All non hydrogen atoms were refined anisotropically. This can be obtained free of charge on application to the Director, CCDC, 12 Union Road, Cambridge CB2 1EZ, UK (fax: +44 1223 336 033; e-mail: deposit@ccdc.cam.ac.uk or www: http://www.ccdc.cam.ac.uk).

\section{Results and discussion}

\subsection{Solubility}

The solubility of TMPP crystal was determined at five different temperatures namely $30,40,45,50$ and $55^{\circ} \mathrm{C}$.

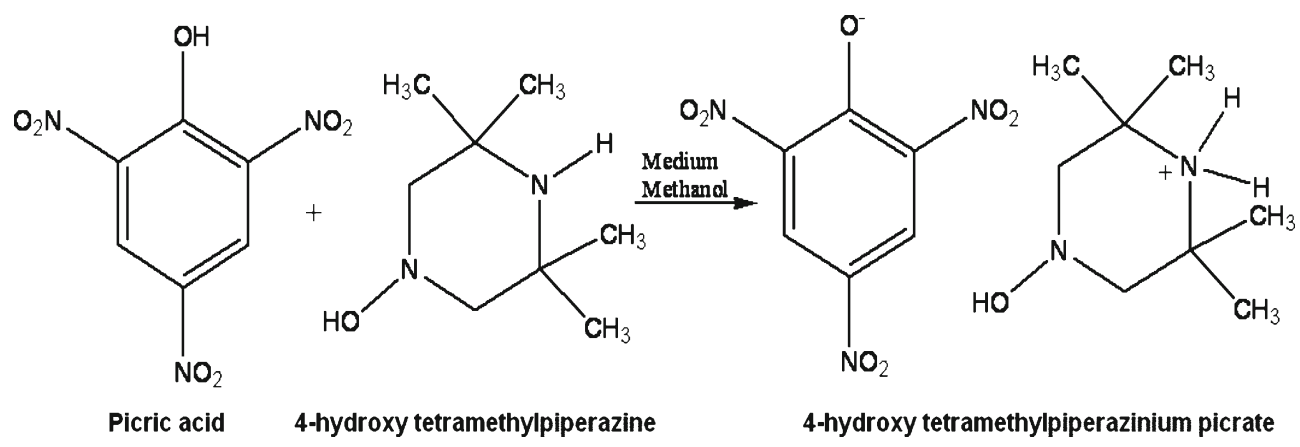

Scheme 1. Formation of TMPP crystal. 


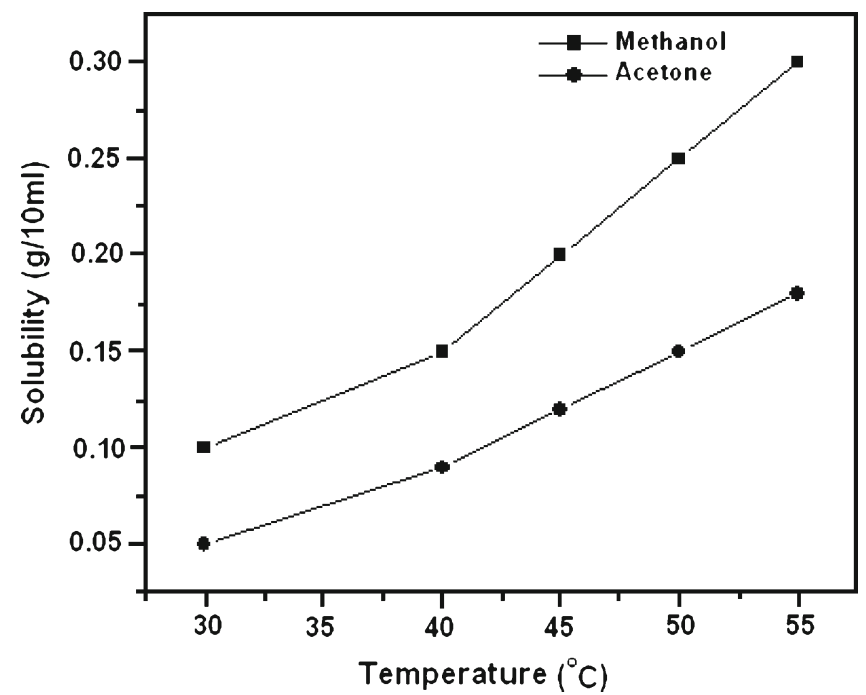

Figure 1. Solubility curve of TMPP crystal.

The measurements were performed dissolving the compound in methanol solvent in a beaker immersed in a constant temperature with continuous stirring. The solubility for $30^{\circ} \mathrm{C}$ was determined by dissolving the TMPP salt in $10 \mathrm{~mL}$ of methanol. A constant volume of $10 \mathrm{~mL}$ of the methanol solution was used throughout the experiment.

The solubility test was carried out with two different solvents viz methanol and acetone. The TMPP crystals were grown from methanolic solution were finely ground into a powder. A known weight of this sample was taken in a beaker immersed in a constant temperature bath (accuracy $\pm 0.01^{\circ} \mathrm{C}$ ). The solvents were added in drops till it just dissolved. The solubility variations of methanol and acetone with different temperatures are shown in figure 1. From the solubility curve, it is observed that the TMPP is more soluble in methanol than in acetone and hence it is easy to grow bulk crystals of TMPP from the methanolic solution by solution growth method. The compound exhibits a high positive solubility-temperature gradient in methanol than in acetone solvents and hence it is suitable for the growth by solution growth method and slow cooling method. The same procedure was repeated for the acetone solvent at different temperatures.

\subsection{Elemental analysis}

The elemental analysis shows that the compound TMPP contains C: $43.42 \%$ (43.37\%), H: $5.28 \%$ (5.42\%) and $\mathrm{N}: 18.22 \%(18.07 \%)$. The results indicate that both experimental and calculated values (given in brackets). The difference between experimental and calculated percentages of carbon, nitrogen and hydrogen are

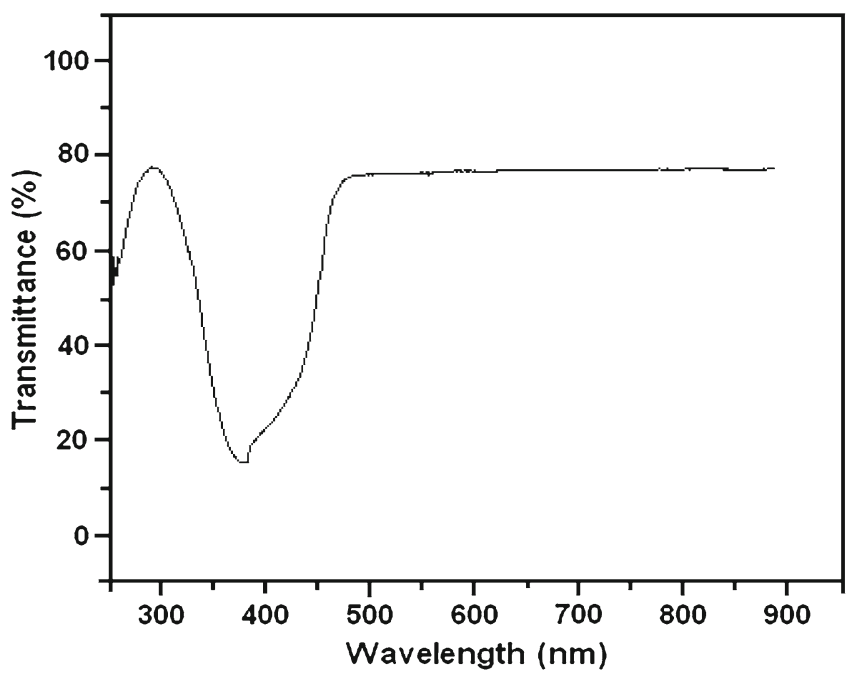

Figure 2. UV-visible spectrum of TMPP crystal.

very close to each other and are within the experimental errors. This, confirms the formation of the compound in the stoichiometric proportion.

\subsection{UV-visible spectral analysis}

The UV-visible transmittance spectrum of the compound is shown in figure 2. The UV-visible spectrum of the material was recorded between 250 and $900 \mathrm{~nm}$. It is observed from the spectrum that the compound shows absorption peak at $370 \mathrm{~nm}$. The absence of absorption in the entire visible region indicates the title material is useful for optoelectronic application. The absorption of the compound is due to the $\pi-\pi^{*}$ transition. The compound has $78 \%$ transparency.

\subsection{Powder X-ray diffraction pattern method}

The experimental and simulated powder X-ray diffraction patterns of TMPP crystals are shown in figure 3 . The sharp and well defined Bragg peaks observed in the powder and simulated X-ray diffraction patterns confirm it crystallinity. The peaks corresponding to 111 and 011 planes have maximum counts of 2600 and 9500 for experimental and simulated patterns, respectively. In order to index these peaks, CRYSFIRE software was utilized to generate the theoretical hkl values for experimental and simulated $\mathrm{X}$-ray diffraction patterns (given in brackets). The calculated unit cell parameters are $\mathrm{a}=6.964 \AA(6.949 \AA), \mathrm{b}=11.8468 \AA$ $(11.7496 \AA), \mathrm{c}=22.1473 \AA(22.1354 \AA)$ and $\alpha=$ $\gamma=90^{\circ}, \beta \neq 90^{\circ}$ indicating that the title compound crystallizes in monoclinic crystal system. The unit cell volume is $1800.27 \AA^{3}\left(1798.12 \AA^{3}\right)$. The unit cell 


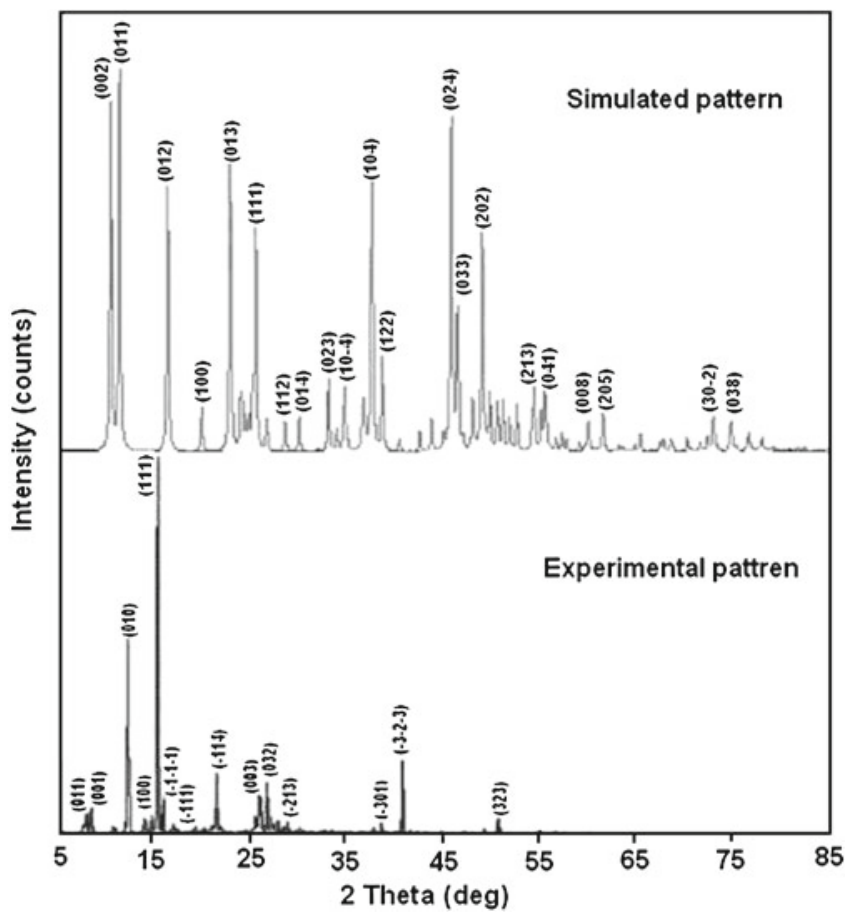

Figure 3. Experimental and simulated powder X-ray diffraction pattern of TMPP crystal.

parameters calculated from powder X-ray diffraction pattern almost fits well with the unit cell parameters obtained from single crystal X-ray diffraction method.

\subsection{Thermal studies}

3.5a TG-DTA analysis: The TG-DTA thermogram of TMPP is shown in figure 4 . When the compound heated from room temperature to $800^{\circ} \mathrm{C}$, the compound decomposes into two stages. The compound is stable up to $140^{\circ} \mathrm{C}$. Afterwards the compound decomposes almost $90 \%$. The first weight loss occurring between 140 and $305^{\circ} \mathrm{C}$. The weight loss for this step is $24 \%$.

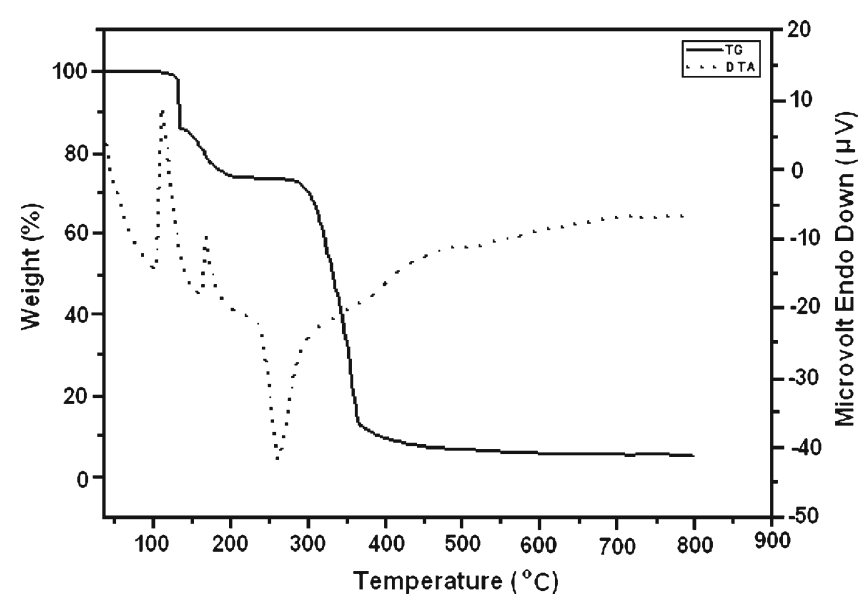

Figure 4. TG/DTA thermogram of TMPP crystal.
This weight loss is due to the loss of nitrogen, two molecules of hydrogen and two molecules of NO. The experimental weight loss for this step is $25 \%$. The difference between formulated and experimental weight losses are very small and are within experimental errors. The second stage weight loss starts at $290^{\circ} \mathrm{C}$ and ends at $860^{\circ} \mathrm{C}$. In this step $67 \%$, weight loss occurs due to the loss of the gaseous products like $2 \mathrm{NO}_{2}, \mathrm{CO}_{2}$ and mixture of hydrocarbons. The experimental weight loss for this step is $65 \%$. The $10 \%$ of the residue remains after $360^{\circ} \mathrm{C}$ which may be due to the presence of residual carbon.

3.5b Differential thermal analysis (DTA): The DTA thermogram (dotted line) of TMPP crystal is depicted in figure 4. There are two endothermic peaks and one exothermic peak observed. The endothermic peaks observed between $103^{\circ} \mathrm{C}$ and $195^{\circ} \mathrm{C}$ are due to the first stage decomposition of the compound. The exothermic peak at $125 \pm 1{ }^{\circ} \mathrm{C}$ is assigned to melting of the compound. The melting point of the compound is $128^{\circ} \mathrm{C}$. The exothermic peak between 210 and $370^{\circ} \mathrm{C}$ is due to the second stage decomposition of the compound. Thus, the DTA study exactly fit with the TG study.

\subsection{Differential scanning calorimetric studies}

The low temperature DSC (heating and cooling) curves of the compound is depicted in figure 5. Thermal anomalies are observed at $5^{\circ} \mathrm{C},-118^{\circ} \mathrm{C}$ and at $142^{\circ} \mathrm{C}$, $-108.5^{\circ} \mathrm{C}$ in the cooling and heating cycles, respectively. The occurrence of thermal hystereses during the cooling and heating cycles indicates a first order phase transition. The first order phase transition may be due to the occurrence of thermal changes in the compound. A first order transition is defined as the one in which a discontinuity occurs in the first derivatives of the free energy with respect to temperature and pressure.

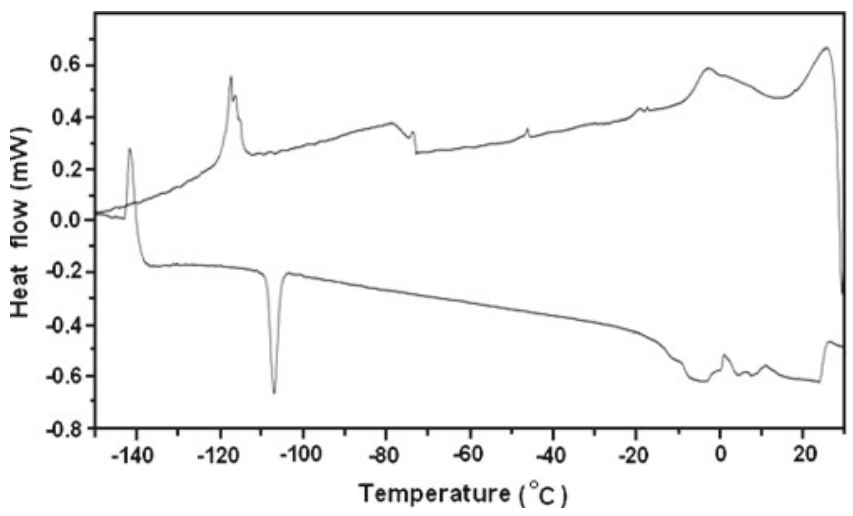

Figure 5. DSC curve of TMPP crystal. 
First order phase transitions are associated with thermal hystereses. ${ }^{15}$

\section{$3.7 \quad$ FTIR spectra}

The FTIR spectrum of the compound (figure 6 a) was compared with FTIR spectra of picric acid (figure $6 \mathrm{~b}$ ) and 4-hydroxy tetramethylpiperazine (figure $6 \mathrm{c}$ ) and are shown in figure $6(\mathrm{a}, \mathrm{b}$ and $\mathrm{c})$. The formation of the charge transfer complex by the reaction between 4-hydroxy tetramethylpiperazine and picric acid is strongly evident by the presence of the main characteristic infrared bands of the donor and acceptor in the spectrum of the product. The bands of the acceptor are shifted to the lower frequencies due to the charge transfer from the donor to the acceptor upon complexation. The -OH peak has disappeared in the spectrum (figure $6 \mathrm{c}$ ) of the product whereas in free picric acid it is observed at $3445 \mathrm{~cm}^{-1}$. The disappearance of the $-\mathrm{OH}$ peak in the compound has been attributed to the transfer of a proton of the donor to the acceptor leading to an intermolecular hydrogen bonding. ${ }^{16}$ The frequency at $3431 \mathrm{~cm}^{-1}$ is due to the N-H asymmetric stretching vibrations. The N-H symmetric stretching vibration is observed at $3051 \mathrm{~cm}^{-1}$. The $\mathrm{C}-\mathrm{H}$ asymmetric stretching vibration is observed at $2851 \mathrm{~cm}^{-1}$ and the corresponding symmetric stretching vibrations are found at 2486 and $2525 \mathrm{~cm}^{-1}$. In the IR spectrum the C-H symmetric stretching vibration of picric acid band is found at $3104 \mathrm{~cm}^{-1}$. The $\mathrm{C}-\mathrm{H}$ stretching vibrations observed in

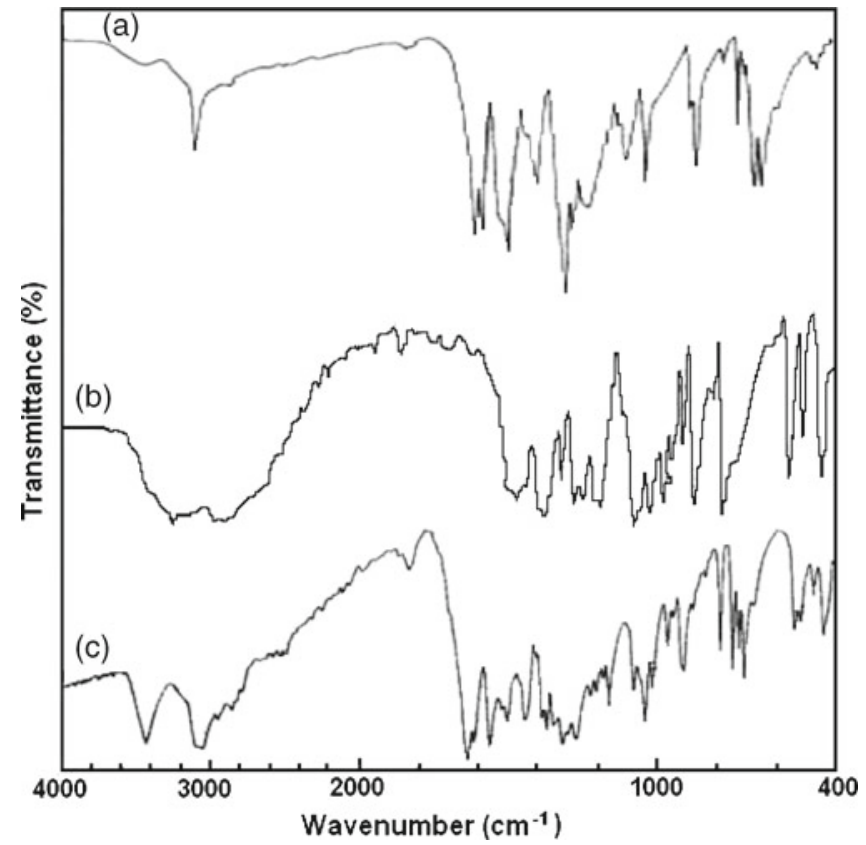

Figure 6. FTIR spectra of (a) picric acid, (b) 4-hydroxy tetramethylpiperazine and (c) TMPP crystal. the compound are shifted to low wavenumber region. The shift in absorption bands is due to the formation of hydrogen bonding in the compound. The absorptions at 1830 and $1633 \mathrm{~cm}^{-1}$ are characteristic of N-H bending vibrations in the compound, whereas in the free picric acid it is observed at $1620 \mathrm{~cm}^{-1}$. The $\mathrm{C}=\mathrm{C}$ stretching vibration is observed at $1595 \mathrm{~cm}^{-1}$. The absorptions at 1500 and $1442 \mathrm{~cm}^{-1}$ are assigned to nitro group asymmetric stretching vibrations. Usually the asymmetric stretching vibration of nitro group is responsible for polar influences and the electronic states of the nucleus. Therefore one can recognize that the shift to low wavenumber of asymmetric stretching vibration of nitro group (1500 and $\left.1442 \mathrm{~cm}^{-1}\right)$ in the complex spectrum compared with the free picric acid $\left(1601 \mathrm{~cm}^{-1}\right)$ is due to the large electron density on the picrate as a result of charge transfer interaction in the complex. The frequency at $1367 \mathrm{~cm}^{-1}$ is due to the presence of $\mathrm{C}-\mathrm{C}$ stretching vibration. The $\mathrm{C}-\mathrm{N}$ stretching vibration is observed at $1317 \mathrm{~cm}^{-1}$. The $\mathrm{C}-\mathrm{O}-\mathrm{C}$ stretching vibration in picric acid is observed at $1280 \mathrm{~cm}^{-1}$. The C-O$\mathrm{C}$ stretching vibration is shifted to lower frequency at $1161 \mathrm{~cm}^{-1}$. The shift in frequency is due to the formation of the intermolecular hydrogen bonding and also polarizable electronegativity group attached. The $\mathrm{C}-\mathrm{O}$ and C-C deformation modes are observed at $1080 \mathrm{~cm}^{-1}$. The frequency at $1016 \mathrm{~cm}^{-1}$ is due to the $\mathrm{OH}$ and $\mathrm{CH}$ out-of-plane bending vibrations. The $\mathrm{CH}_{2}$ rocking vibration in the phenyl ring is observed at $910 \mathrm{~cm}^{-1}$.

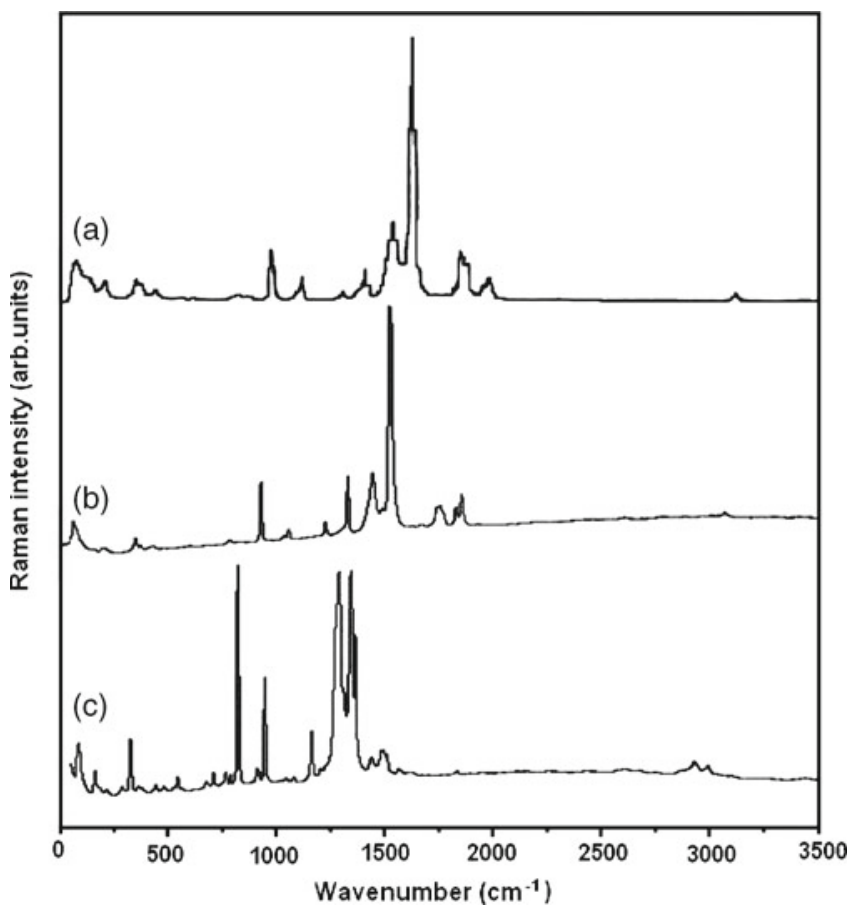

Figure 7. Polarized Raman spectra of (a) picric acid, (b) 4-hydroxy tetramethylpiperazine and (c) TMPP crystal. 
Table 1. Crystallographic data and structure refinements of TMPP crystal.

Empirical formula

Formula weight

Temperature

Wavelength

Crystal system

Space group

Cell dimensions

Volume

Z

Density (calculated)

Absorption coefficient

$\mathrm{F}_{000}$

Crystal size

Reflections collected

Range for data collection (deg)

Number parameters

Calculated density $\left(\mathrm{g} / \mathrm{m}^{3}\right)$

Absorption correction

Max. and min. transmission

Limiting indices h, k, 1

Refinement method

Goodness-of-fit on F2

Final $\mathrm{R}$ indices

$\mathrm{R}$ indices (all data)

Largest diff. peak and hole

Structure determination

Refinement

$R_{\text {int }}$

CCDC number
$\mathrm{C}_{14} \mathrm{H}_{21} \mathrm{~N}_{5} \mathrm{O}_{8}$

387.36

298(2) K

$0.71073 \AA$

Monoclinic

$\mathrm{P} 2(1) / \mathrm{c}$

$\mathrm{a}=6.9513(8) \AA, \mathrm{b}=11.8016(14) \AA$,

$\mathrm{c}=22.018(2) \AA, \alpha=90.00^{\circ}, \beta=92.575(2)^{\circ}$

$\gamma=90.00^{\circ}$

1804.5(4) $\AA^{3}$

4

$1.645 \mathrm{mg} / \mathrm{m}^{3}$

$0.139 \mathrm{~mm}^{-1}$

712

$0.30 \times 0.22 \times 0.18 \mathrm{~mm}^{3}$

3051

$2.23-26.00^{\circ}$

245

1.645

Semi-empirical from equivalents 0.9499 and 0.9930

$-11 / 11,-14 / 14,-15 / 15$

Full-matrix least-squares on F2

1.098

$\mathrm{R} 1=0.0995, \mathrm{wR} 2=0.2627$

$\mathrm{R} 1=0.0848, \mathrm{wR} 2=0.2452$

0.411 and -0.485 e. $\AA^{-3}$

SHELXS-97

SHELXL-97

0.026

838801

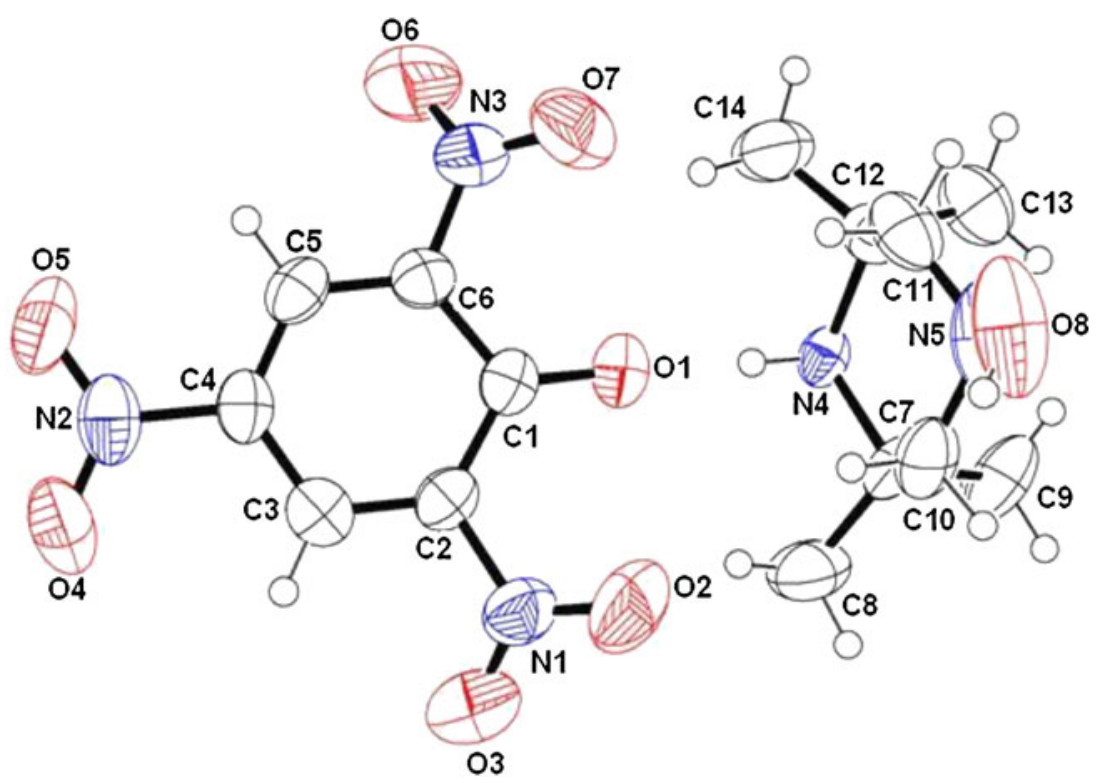

Figure 8. ORTEP diagram of TMPP with $50 \%$ probability. 
The absorption at $779 \mathrm{~cm}^{-1}$ is assigned to C-C bending vibration. The nitro group and phenyl ring out-ofplane bending vibrations are observed at $740 \mathrm{~cm}^{-1}$. The nitro group out-of-plane bending vibration is shifted to lower frequency compared to free picric acid. The frequency at $540 \mathrm{~cm}^{-1}$ is characteristic of nitro group rocking vibration. The $\mathrm{C}-\mathrm{N}-\mathrm{C}$ stretching mode vibration is observed at 476 and $441 \mathrm{~cm}^{-1} \cdot{ }^{17}$

\subsection{Polarized Raman spectra}

The polarized Raman spectrum of the compound is shown in figure $7 \mathrm{c}$ for sake of reference the polarized Raman spectra of picric acid and 4-hydroxy tetramethylpiperazine are shown in figure $7 \mathrm{a}$ and $\mathrm{b}$. The small broad (figure 7 a) peak at $3350 \mathrm{~cm}^{-1}$ is due to the presence of -OH stretching vibration in picric acid. The absence of $-\mathrm{OH}$ stretching vibration confirms a proton transfer from picric acid to 4-hydroxy tetramethylpiperazine molecule with the formation of picrate anion and 4-hydroxy tetramethylpiperazinium cation. ${ }^{18}$ The $\mathrm{N}-\mathrm{H}$ stretching vibration is found at $3001 \mathrm{~cm}^{-1}$. The absorption peak at $2955 \mathrm{~cm}^{-1}$ is due to $\mathrm{C}-\mathrm{H}$ asymmetric stretching vibration. The $\mathrm{C}-\mathrm{H}$ vibration for free picric acid is observed at $3110 \mathrm{~cm}^{-1}$. The $\mathrm{C}-\mathrm{H}$ stretching vibrations are shifted to lower wavenumber region due to the electronegativity of the nitro group attached. ${ }^{19}$ The C-N stretching vibration is observed at $1503 \mathrm{~cm}^{-1}$. Peaks in the region $1860-2722 \mathrm{~cm}^{-1}$ are caused by sum

Table 2. Selected bond distances of TMPP crystal.

\begin{tabular}{lccc}
\hline O1-C1 & $1.252(4)$ & N5-C11 & $1.505(7)$ \\
O2-N1 & $1.217(5)$ & C7-C10 & $1.528(6)$ \\
O3-N1 & $1.180(6)$ & C7-C9 & $1.534(6)$ \\
O4-N2 & $1.226(5)$ & C7-C8 & $1.536(6)$ \\
O5-N2 & $1.214(5)$ & C8-H8A & 0.9600 \\
O6-N3 & $1.198(5)$ & C8-H8B & 0.9600 \\
O7-N3 & $1.238(5)$ & C8-H8C & 0.9600 \\
N1-C2 & $1.440(5)$ & C9-H9A & 0.9600 \\
N2-C4 & $1.443(5)$ & C9-H9B & 0.9600 \\
N3-C6 & $1.442(5)$ & C9-H9C & 0.9600 \\
C1-C2 & $1.443(5)$ & C10-H10A & 0.9700 \\
C1-C6 & $1.456(5)$ & C10-H10B & 0.9700 \\
C2-C3 & $1.369(5)$ & C11-C12 & $1.526(5)$ \\
C3-C4 & $1.379(5)$ & C11-H11A & 0.9700 \\
C3-H3 & 0.9300 & C11-H11B & 0.9700 \\
C4-C5 & $1.372(5)$ & C12-C13 & $1.513(6)$ \\
C5-C6 & $1.360(5)$ & C12-C14 & $1.528(6)$ \\
C5-H5 & 0.9300 & C13-H13A & 0.9600 \\
O8-N5 & $1.457(5)$ & C13-H13B & 0.9600 \\
O8-H8 & 0.8200 & C13-H13C & 0.9600 \\
N4-C7 & $1.524(4)$ & C14-H14A & 0.9600 \\
N4-C12 & $1.525(4)$ & C14-H14B & 0.9600 \\
N4-H4A & 0.9000 & C14-H14C & 0.9600 \\
N4-H4B & 0.9000 & N5-C10 & $1.500(7)$ \\
\hline
\end{tabular}

tones. In the Raman spectra, these tones are usually absent, which confirm the assignment. The asymmetric stretching vibrations of the nitro group are observed at $1426 \mathrm{~cm}^{-1}$ in the compound, whereas in the free picric acid it is observed at $1562 \mathrm{~cm}^{-1}$. This shift has been attributed to the charge transfer from donor to acceptor upon complexation. In the Raman spectrum the hydrogen bond is not revealed as usual. The nitro group has characteristic vibrations active in both IR and Raman spectra. The peaks at 1338 and $1282 \mathrm{~cm}^{-1}$ are characteristic symmetric vibrations of nitro groups and ring carbon stretching vibrations, respectively. ${ }^{20}$ The appearance of a peak at $1162 \mathrm{~cm}^{-1}$ in the compound

Table 3. Selected bond angles of TMPP crystal.

\begin{tabular}{|c|c|c|c|}
\hline $\mathrm{O} 3-\mathrm{N} 1-\mathrm{O} 2$ & $121.5(4)$ & C9-C7-C8 & $109.6(4)$ \\
\hline $\mathrm{O} 3-\mathrm{N} 1-\mathrm{C} 2$ & $119.6(4)$ & C7-C8-H8A & 109.5 \\
\hline $\mathrm{O} 2-\mathrm{N} 1-\mathrm{C} 2$ & $118.9(4)$ & C7-C8-H8B & 109.5 \\
\hline $\mathrm{O} 5-\mathrm{N} 2-\mathrm{O} 4$ & $122.0(4)$ & H8A-C8-H8B & 109.5 \\
\hline O5-N2-C4 & $118.6(4)$ & C7-C8-H8C & 109.5 \\
\hline $\mathrm{O} 4-\mathrm{N} 2-\mathrm{C} 4$ & $119.5(4)$ & H8A-C8-H8C & 109.5 \\
\hline O6-N3-O7 & $122.9(4)$ & H8B-C8-H8C & 109.5 \\
\hline O6-N3-C6 & $119.0(4)$ & C7-C9-H9A & 109.5 \\
\hline O7-N3-C6 & $118.1(4)$ & C7-C9-H9B & 109.5 \\
\hline $\mathrm{O} 1-\mathrm{C} 1-\mathrm{C} 2$ & $125.3(3)$ & H9A-C9-H9B & 109.5 \\
\hline $\mathrm{O} 1-\mathrm{C} 1-\mathrm{C} 6$ & $123.2(3)$ & C7-C9-H9C & 109.5 \\
\hline C2-C1-C6 & $111.4(3)$ & H9A-C9-H9C & 109.5 \\
\hline $\mathrm{C} 3-\mathrm{C} 2-\mathrm{N} 1$ & $116.4(3)$ & H9B-C9-H9C & 109.5 \\
\hline $\mathrm{C} 3-\mathrm{C} 2-\mathrm{C} 1$ & $124.4(3)$ & N5-C10-C7 & $113.5(3)$ \\
\hline $\mathrm{N} 1-\mathrm{C}-\mathrm{C} 1$ & $119.2(3)$ & N5-C10-H10A & 108.9 \\
\hline $\mathrm{C} 2-\mathrm{C} 3-\mathrm{C} 4$ & 119.3(3) & C7-C10-H10A & 108.9 \\
\hline C2-C3-H3 & 120.3 & N5-C10-H10B & 108.9 \\
\hline C4-C3-H3 & 120.3 & C7-C10-H10B & 108.9 \\
\hline C5-C4-C3 & $120.8(3)$ & H10A-C10-H10B & 107.7 \\
\hline $\mathrm{C} 5-\mathrm{C} 4-\mathrm{N} 2$ & $120.0(3)$ & N5-C11-C12 & $114.0(3)$ \\
\hline $\mathrm{C} 3-\mathrm{C} 4-\mathrm{N} 2$ & $119.3(3)$ & N5-C11-H11A & 108.8 \\
\hline C6-C5-C4 & $120.1(3)$ & C12-C11-H11A & 108.8 \\
\hline C6-C5-H5 & 120.0 & N5-C11-H11B & 108.8 \\
\hline C4-C5-H5 & 120.0 & C12-C11-H11B & 108.8 \\
\hline C5-C6-N3 & $117.5(3)$ & H11A-C11-H11B & 107.6 \\
\hline C5-C6-C1 & $123.9(3)$ & C13-C12-N4 & $105.3(3)$ \\
\hline N3-C6-C1 & $118.6(3)$ & C13-C12-C11 & $112.0(4)$ \\
\hline N5-O8-H8 & 109.5 & N4-C12-C11 & $106.0(3)$ \\
\hline C7-N4-C12 & $120.1(3)$ & C13-C12-C14 & $108.4(4)$ \\
\hline C7-N4-H4A & 107.3 & N4-C12-C14 & $111.8(3)$ \\
\hline C12-N4-H4A & 107.3 & C11-C12-C14 & $113.2(3)$ \\
\hline C7-N4-H4B & 107.3 & C12-C13-H13A & 109.5 \\
\hline C12-N4-H4B & 107.3 & C12-C13-H13B & 109.5 \\
\hline H4A-N4-H4B & 106.9 & H13A-C13-H13B & 109.5 \\
\hline O8-N5-C10 & $109.6(4)$ & C12-C13-H13C & 109.5 \\
\hline O8-N5-C11 & $106.9(4)$ & H13A-C13-H13C & 109.5 \\
\hline C10-N5-C11 & 111.1(3) & H13B-C13-H13C & 109.5 \\
\hline N4-C7-C10 & $106.5(3)$ & C12-C14-H14A & 109.5 \\
\hline N4-C7-C9 & $105.1(3)$ & C12-C14-H14B & 109.5 \\
\hline C10-C7-C9 & $111.3(4)$ & H14A-C14-H14B & 109.5 \\
\hline N4-C7-C8 & $110.1(3)$ & C12-C14-H14C & 109.5 \\
\hline C10-C7-C8 & $113.8(3)$ & H14A-C14-H14C & 109.5 \\
\hline H14B-C14-H14C & 109.5 & & \\
\hline
\end{tabular}




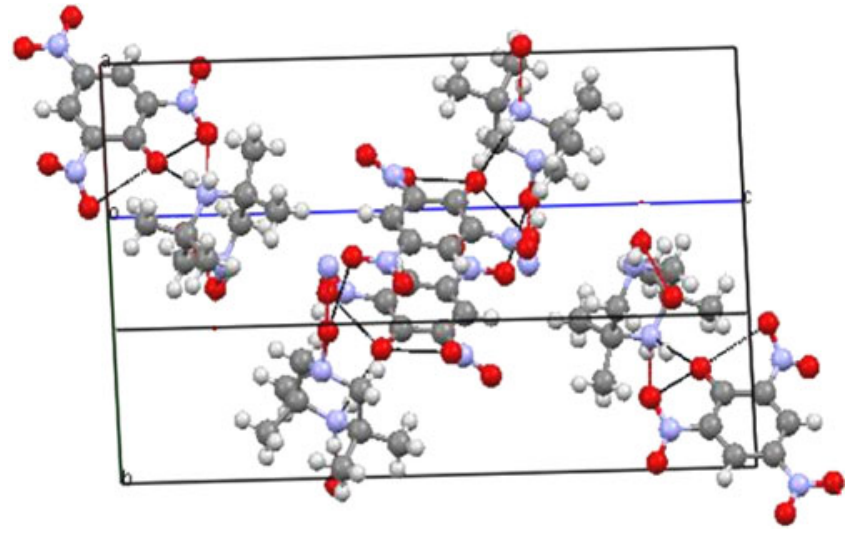

Figure 9. Crystal packing diagram of TMPP crystal along the 'b' axis.

is attributed to the $\mathrm{C}-\mathrm{O}$ stretching mode due to the coordination of phenolic oxygen after deprotonation. ${ }^{21}$ The frequency found at $941 \mathrm{~cm}^{-1}$ is due to the $\mathrm{C}-\mathrm{H}$ out-of-plane bending vibration. The peak at $810 \mathrm{~cm}^{-1}$ is assigned to $\mathrm{C}-\mathrm{H}$ and nitro deformation vibrations. The $\mathrm{CH}_{2}$ rocking vibration is observed at $710 \mathrm{~cm}^{-1}$ and the $\mathrm{C}-\mathrm{C}-\mathrm{O}$ deformation mode vibration is observed at $534 \mathrm{~cm}^{-1}$. The frequency at $326 \mathrm{~cm}^{-1}$ is due to C-C-C out-of-plane bending vibration. ${ }^{22}$ The lattice vibrations of molecules are found at 160 and $83 \mathrm{~cm}^{-1}$.

\subsection{NLO property}

The nonlinear optical property of the grown crystal was tested using Kurtz-Perry powder technique by passing a Q-switched, mode locked Nd:YAG laser of $1064 \mathrm{~nm}$ and pulse width of $8 \mathrm{~ns}$ (spot radius of $1 \mathrm{~mm}$ ) on the powder sample of TMPP. The input laser beam was passed through an IR reflector and then directed on the microcrystalline powdered sample. Photodiode detector and oscilloscope assembly detected the green light emitted by the sample. The second harmonic generation efficiency of the crystal was evaluated by taking the microcrystalline powder of KDP as the reference material. For a laser input pulse of $6.9 \mathrm{~mJ}$, the SHG signal $(532 \mathrm{~nm})$ of $20 \mathrm{mV}$ and $36 \mathrm{mV}$ were obtained for KDP and samples, respectively. Hence, it is observed that the SHG efficiency of TMPP is 1.5 times greater than that of KDP.

\subsection{Single crystal X-ray diffraction method}

All single crystal X-ray measurements were made at room temperature using suitable crystals for data collection. Accurate lattice parameters were determined from least squares refinements of well-centered reflections in the ranges $2.91 \theta \mathrm{u} \theta 26.02$ for TMPP crystals. The crystal structure of 4-hydroxy tetramethylpiperazine picrate crystal was determined by single crystal $\mathrm{X}$-ray analysis.

As-grown single crystals of TMPP were obtained from methanol solution. It belongs to the monoclinic crystal system with space group P2(1)/c. The lattice parameters obtained are $\mathrm{a}=6.9513(8) \AA$, $\mathrm{b}=11.8016(14) \AA, \mathrm{c}=22.018(2) \AA, \alpha=90.00^{\circ}$,

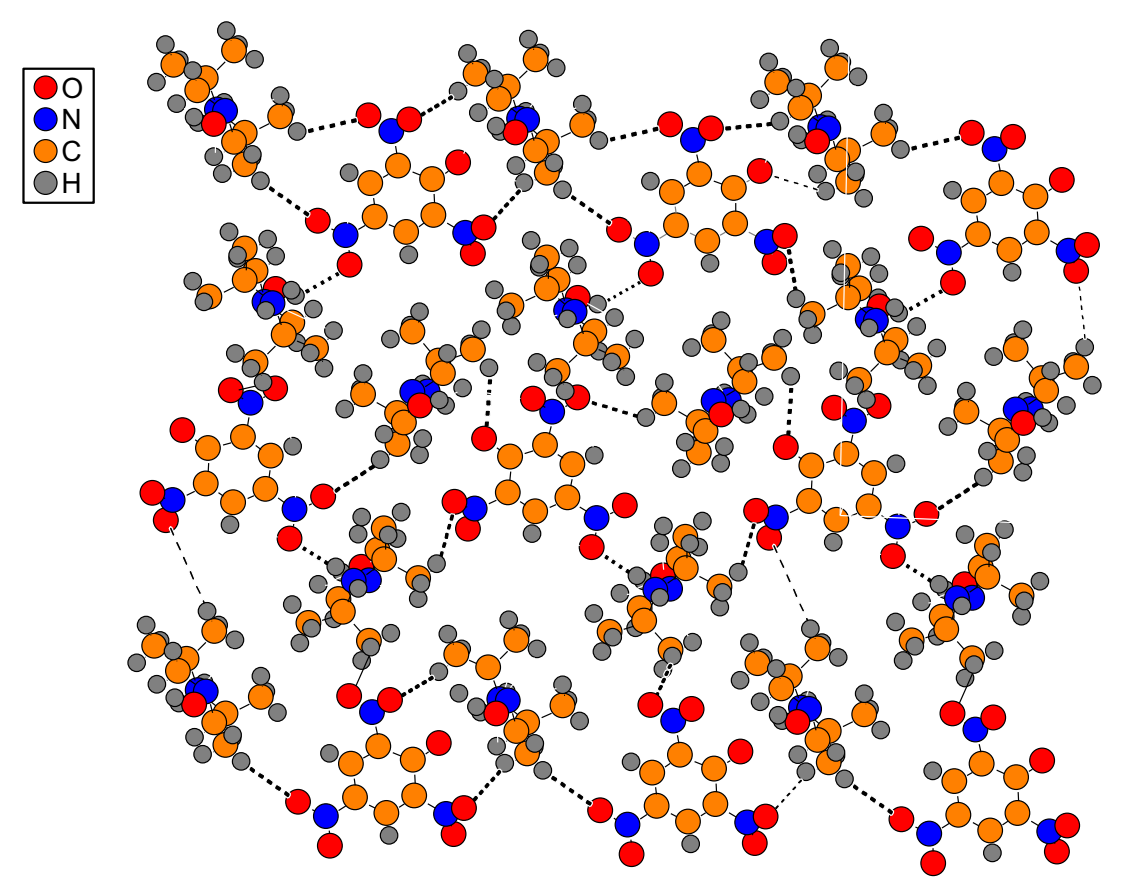

Figure 10. Two-dimensional (2D) crystal packing diagram of TMPP crystal. 
Table 4. Hydrogen bonding parameters $\left(\AA\right.$ and $\left.^{\circ}\right)$ of TMPP crystal.

\begin{tabular}{|c|c|c|c|c|}
\hline $\mathrm{D}-\mathrm{H} \cdots \mathrm{A}$ & $d(D-H) \AA$ & $\mathrm{d}(\mathrm{H} \cdots \mathrm{A}) \AA$ & $\mathrm{d}(\mathrm{D} \cdots \mathrm{A}) \AA$ & $<(\mathrm{DHA})^{\circ}$ \\
\hline 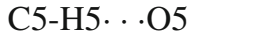 & 0.81 & 2.79 & $3.372(4)$ & $130(2)$ \\
\hline 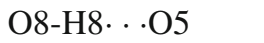 & 0.82 & 2.42 & $3.023(5)$ & 130.7 \\
\hline C11-H11A $\cdots$ O7 & 0.97 & 2.69 & $3.554(6)$ & 149.1 \\
\hline C14-H14C...O7 & 0.96 & 2.83 & $3.660(6)$ & 145.3 \\
\hline C13-H13B . .O4 & 0.96 & 2.89 & $3.659(6)$ & 137.4 \\
\hline C9-H9C ‥O8 & 0.96 & 2.86 & $3.566(7)$ & 131.1 \\
\hline C8-H8A...O3 & 0.96 & 2.68 & $3.472(9)$ & 139.8 \\
\hline
\end{tabular}

Symmetry transformations used to generate equivalent atoms: (\#1) $-\mathrm{x}, 0.5+\mathrm{y}, 0.5-\mathrm{z}$, (\#2) -1+x, y, z, (\#3) x, 1+y, z, (\#4) 1-x, 2-y,1-z, (\#5) 1-x, 1-y, 1-z

$\beta=92.575(2)^{\circ}, \gamma=90.00^{\circ}$ and the unit cell volume is $1804.5(4) \AA^{3}$. The unit cell parameters determined by powder X-ray diffraction method and the single crystal X-ray diffraction method are similar. However, there is a very small change in the cell volume $\left(4.27 \AA^{3}\right)$. It is observed from both the powder and single crystal $\mathrm{X}$-ray diffraction methods that the ' $\mathrm{c}$ ' axis is large compared to ' $a$ ' and ' $b$ ' axes. This may be due to anisotropic thermal expansion. The crystal data and structure refinements of TMPP are given in table 1. The ORTEP diagram of the crystal is illustrated in figure 8.

The 4-hydroxy tetramethylpiperazine molecule appears in the crystalline lattice as a single protonated cation and the picrate molecule is present as a deprotonated anion. X-ray single crystal structure of the proton-transfer complex of 4-hydroxy tetramethylpiperazine with picric acid shows the presence of mono protonated 4-hydroxy tetramethylpiperazine cation and gives intermolecular hydrogen bonding associations. In case of neutral picric acid there exists hydrogen bond between $\mathrm{NO}_{2}$ and hydroxyl group of the picric acid itself. The orientation of $\mathrm{NO}_{2}$ group is stabilized by intramolecular interaction with the $\mathrm{H}$ atoms (O4-H3 and $\mathrm{O} 5-\mathrm{H} 5)$.

The selected bond distances and angles are presented in tables 2 and 3, respectively. Crystal packing diagram of TMPP crystal along the 'b'axis is shown in figure 9 . The loss of a proton in the picrate anion is confirmed by the lengthening of the $\mathrm{C}-\mathrm{C}$ bonds. In the picrate anion, removal of the phenol $\mathrm{H}$ atom leads to a shortening of the C1-O1, (1.252(4)) bond distance, while the C1-C2 and C1-C6 bond distances (1.443(5) and 1.456(5) $\mathrm{A}$, respectively) increases. It has been found that in most picrates the ortho-related nitro groups, which are commonly involved in hydrogen-bonding interactions are more likely to be rotated out of the molecular plane (a)

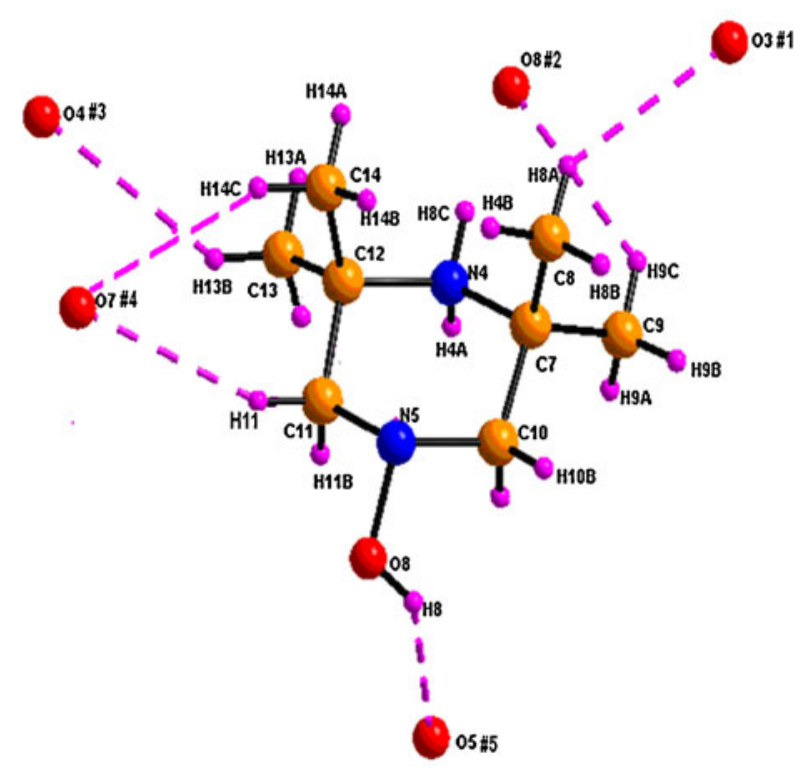

(b)

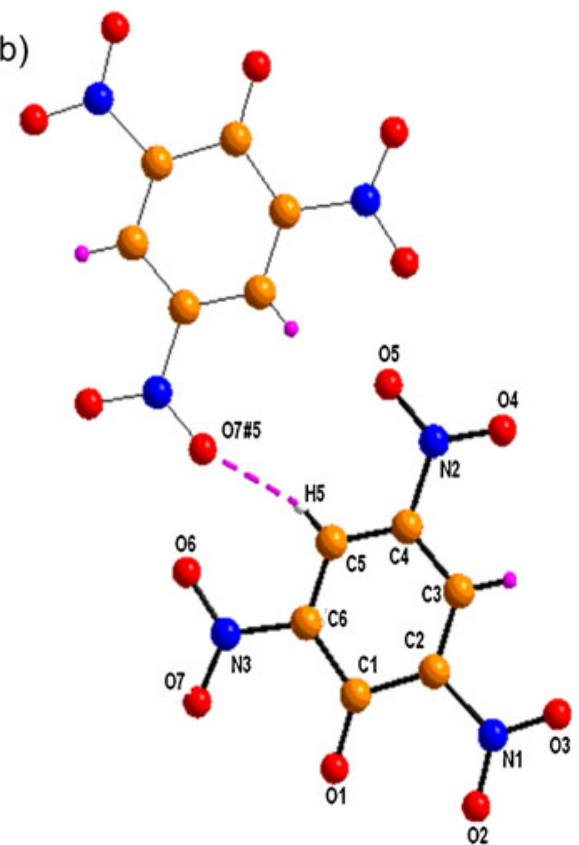

Figure 11. Hydrogen bonding environment around each cation and anion (11a and 11b). Color codes: $\mathrm{O}$, red; $\mathrm{C}$, magenta; $\mathrm{N}$, blue; $\mathrm{H}$, black. 


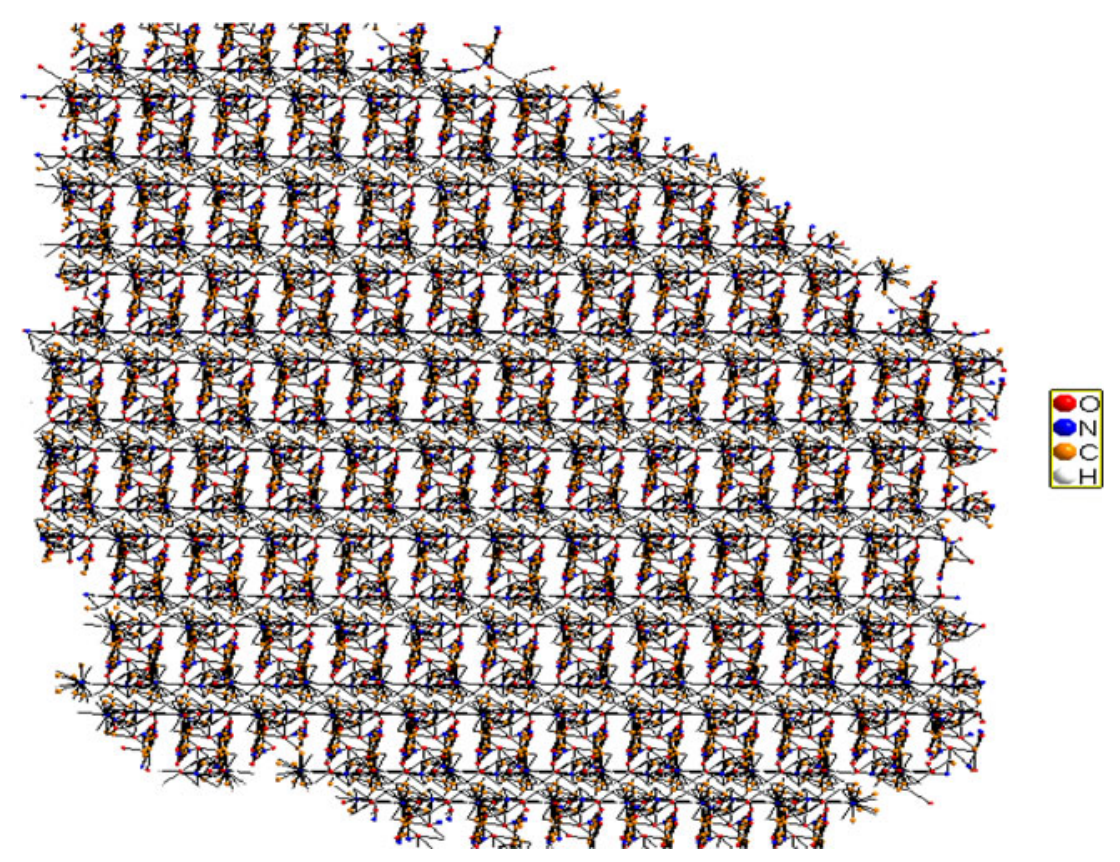

Figure 12. Three-dimensional (3D) framework of the compound because of $\mathrm{C}-\mathrm{H} \cdots \mathrm{O}, \mathrm{N}-\mathrm{H} \cdots \mathrm{O}$ and $\mathrm{N}-\mathrm{H}$. . N supramolecular interactions.

than the para nitro substituent. ${ }^{23}$ Here, even though one of the ortho nitro groups is not involved in hydrogen bonding, it is still twisted from the plane of the ring, while the para nitro group lies approximately in the ring plane. It is also found that the twisting of these nitro groups is independent of C-N bond distances. ${ }^{24}$

The repulsive interactions of the deprotonated oxygen atom $\mathrm{O} 1$ with the electron withdrawing $\mathrm{NO}_{2}$ groups attached in the ortho positions in relation to the $\mathrm{O} 1$ are responsible for the lengthening of the $\mathrm{C} 2-\mathrm{C} 3,1.369(5)$ and C5-C6, 1.360(5) bonds as well as for the significant differences between the internal $\mathrm{C}-\mathrm{C}-\mathrm{C}$ angles within the ring. Both $\mathrm{C}-\mathrm{C}-\mathrm{C}$ angles joining the $\mathrm{NO}_{2}$ groups (C1-C2-C3, 124.4(3) and C1-C6-C5, 123.9(3)) are significantly greater and the C2-C1-C6, 111.4(3) angle joining the deprotonated hydroxyl group is significantly smaller than the expected angle for carbon $\mathrm{sp}^{2}$ hybridization. The torsion angles O7-N3-C6-C1 and O2-N1-C2-C1 describing the orientation of the $\mathrm{NO}_{2}$ groups in relation to the plane of the ring are $-37.8(5)^{\circ}$ and $27.4(6)^{\circ}$, respectively. This suggests that the out of three $\mathrm{NO}_{2}$ groups, the conformation of the both ortho $\mathrm{NO}_{2}$ groups are out of the ring and para $\mathrm{NO}_{2}$ groups is plane of the ring.

The two-dimensional (2D) crystal packing diagram of TMPP crystal is shown in figure 10. The packing of molecules in the lattice is determined by conventional and unconventional C-H. . O hydrogen bonds. In addition to the conventional hydrogen bonds the short $\mathrm{C}-\mathrm{H}$. . O intramolecular contacts between $\mathrm{C} 3-\mathrm{H} 3$ or
C5-H5 and nitro groups are observed. This is an important feature in all-aromatic picrate complexes. ${ }^{25}$ All amine $\mathrm{H}$ atoms participated in hydrogen bonding are acceptor. The hydrogen bonded network of the complex clearly shows that the counter TMPP cation part is joined to the counter picrate anion via extensive hydrogen bonding. These hydrogen bonds are responsible for the stability of TMPP compound. The hydrogen bonding parameters are presented in table 4 . The hydrogen bonding environments around each of the cation and anion are shown by $\mathrm{C}-\mathrm{H} \cdot \cdots \mathrm{O}, \mathrm{N}-\mathrm{H} \cdot \cdots \mathrm{N}$ and $\mathrm{N}-\mathrm{H} . \mathrm{O}$ interactions and the picture are given in figures $11 \mathrm{a}$ and $\mathrm{b}$, respectively. In this structure six hydrogen bonding interactions around the cation and one hydrogen bonding interaction around the anion are observed. In the 4-hydroxy tetramethylpiperazine molecule there are possible four interactions for all the methyl groups, C8-H8(A), C9-H9(C), C9-H9(A) and C13-H13(B). Symmetry transformations used to generate equivalent atoms are $(\# 1)-x, 0.5+y, 0.5-z,(\# 2)$ $-1+x, y, z,(\# 3) x, 1+y, z,(\# 4) 1-x, 2-y, 1-z,(\# 5)$ $1-\mathrm{x}, 1-\mathrm{y}, 1-\mathrm{z}$. There are four methyl groups attached with 4-hydroxy tetramethylpiperazine molecule. The C$\mathrm{H}$. . O distances for all the methyl groups interaction lie in the 3.472(9), 3.566(7), 3.659(6) and 4-3.660(6). These distances indicate that all the methyl groups deviated from the plane of the 4-hydroxy tetramethylpiperazine ring. So it is observed that the 4-hydroxy tetramethylpiperazine ring is somewhat distorted from the original structure. It is difficult to assess, which groups 
are more strongly engaged in attraction with oxygen atoms, because this depends not only on the $\mathrm{C}-\mathrm{H} \cdots \mathrm{O}$ distance but also on the $\mathrm{C}-\mathrm{H}$. . O angle. The threedimensional (3D) diagram of TMPP crystal is shown in figure 12 .

\section{Conclusion}

Single crystals of TMPP were grown by slow evaporation method at room temperature. The solubility of the crystal was analysed by two different solvents. The stoichiometric ratio of the compound was confirmed by $\mathrm{C} \mathrm{H} \mathrm{N}$ analysis. The UV-visible transmission spectrum revealed the nonlinear optical properties of the grown crystals with a transparency of $75 \%$. The crystallinity of the compound was confirmed by powder X-ray diffraction pattern. The TG-DTA analysis was carried out to find the thermal stability of the synthesized crystal. Thermal anomalies observed in the DSC curves indicate the title compound shows a first order phase transition. The presence of various functional groups in the compound were studied by FTIR and polarized Raman spectroscopic techniques. The crystal structure of the grown crystal was determined by single crystal X-ray diffraction method and was found that the compound crystallizes in monoclinic system. Kurtz and Perry powder SHG technique was used to analyze the NLO property of the compound and the SHG efficiency of the compound was found to be 1.5 times greater than that of KDP.

\section{Acknowledgements}

The authors gratefully acknowledge the School of Chemistry, University of Hydrabad, Hyderabad for their instrumental facilities. One of the authors TD, thanks the UGC-Networking Centre, School of Chemistry, University of Hydrabad, Hyderabad for the measurement of single crystal X-ray diffraction analysis. We are also thankful to Prof. P.K. Das, Indian Institute of Science (IPC, IISC), Bangalore for NLO measurements.

\section{References}

1. Yamaguchi S, Goto M, Takayanagi H and Ogura H 1988 Bull. Chem. Soc. Jpn. 611026
2. Nagata H, Doi M, Ishida T and Wakahara A 1997 Acta Crystallogr. C 53367

3. Zaderenko P, Gel S M, Lopez P, Ballesteros P, Fonseco I and Albert A 1997 Acta Crystallogr. B 53961

4. Mallik T and Kar T 2007 Mater. Lett. 613826

5. Sun Z H, Zhang G H, Wang X Q, Cheng X F, Liu X J, Zhu L, Fan Y, Yu G and Xu D 2008 J. Cryst. Growth 310 2842

6. Datta A and Pati S K 2003 J. Chem. Phys. 1188420

7. De Matos G, Venkataraman V, Nogueria E, Belsley M, Criado P A, Dianez M J and Garrido E P 2000 Synth. Met. 115225

8. Chemla D S and Zyss J 1987 Nonlinear optical properties of organic molecules and crystals (New York: Academic Press) Vols I \& II

9. Criado A, Dianez M J, Garrido S P L, Fernandes I M, Belsley M E and De Gomes M 2000 Acta Crystallogr. C $\mathbf{5 6} 888$

10. Zaccaro J, Salvestrini J P, Ibanez A, Ney P and Fontana M D 2000 J. Opt. Soc. Am. 17427

11. Sheldrick G M 1998 Software for the CCD detector system (Madison, WI: Bruker analytical X-ray systems Inc)

12. Sheldrick G M 1996 SADABS A program for absorption correction with the Siemens SMART area-detector system (Germany: University of Göttingen)

13. Sheldrick G M 1997 SHELXS-97 A program for solution of crystal structures (Germany: University of Göttingen)

14. Sheldrick G M 1997 SHELXL-97 A program for solution of crystal structures (Germany: University of Göttingen)

15. Rao C N R and Gopalakrishnan J 1997 New directions in solid state chemistry (2nd edn. Cambridge: Cambridge University Press) p. 169

16. Teleb S M and Gaballa A S 2005 Spectrochim. Acta Part A 62140

17. Ghazaryan V V, Fleck M and Petrosyan A M 2011 Spectrochim. Acta Part A $\mathbf{7 8} 128$

18. Janczak J and Perpetuo G J 2010 J. Mol. Struct. 965166

19. Rajkumar B J M and Ramakrishnan V 2001 Spectrochim. Acta Part A $\mathbf{5 7} 254$

20. Maruya R C, Sharma P and Roy S 2003 Syn. React. Inorg. Metal. Chem. 33683

21. Briget Mary M, Sasirekha V and Ramakrishnan V 2006 Spectrochim. Acta Part A 65955

22. Briget Mary $M$, Umadevi $M$, Pandiarajan $S$ and Ramakrishnan V 2004 Spectrochim. Acta Part A 60 2643

23. Anitha K, Sridhar B and Rajaram R K 2004 Acta Crystallogr. E $\mathbf{6 0} 1530$

24. Kai T, Goto M, Furuhata K and Takayanagi H 1994 Anal. Sci. 10359

25. Sawka-Dobrowolska W, Bator G, Sobczyk L, Grech E, Nowicka-Scheibe J, Pawlukojc A and Wuttke J $2010 \mathrm{~J}$. Mol. Struct. 975298 